\title{
Inter- and intraspecific variation of spider mite susceptibility to fungal infections: Implications for the long-term success of biological control
}

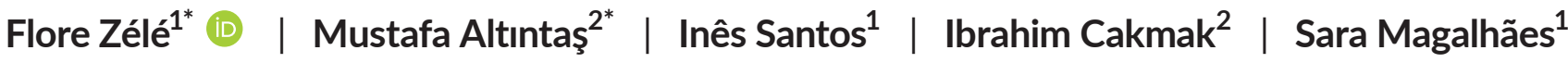

${ }^{1}$ Centre for Ecology, Evolution and Environmental Changes (cE3c), Faculdade de Ciências, Universidade de Lisboa, Lisboa, Portugal

${ }^{2}$ Department of Plant Protection, Faculty of Agriculture, Adnan Menderes University, Aydin, Turkey

\section{Correspondence}

Flore Zélé, Centre for Ecology, Evolution and Environmental Changes (cE3c), Faculdade de Ciências, Universidade de Lisboa, Edificio C2, $3^{\circ}$ Piso Campo Grande, 1749-016

Lisboa, Portugal.

Email: fezele@fc.ul.pt

Funding information

FCT-Tubitak, Grant/Award Number: FCT-TUBITAK/0001/2014 and TUBITAK TOVAG 1150610; Adnan Menderes University Research Foundation, Grant/ Award Number: ZRF-17055; FCT Post-Doc fellowship, Grant/Award Number: SFRH/ BPD/125020/2016; cE3c FCT Unit, Grant/ Award Number: UID/BIA/00329/2020

\begin{abstract}
Spider mites are severe pests of several annual and perennial crops worldwide, often causing important economic damages. As rapid evolution of pesticide resistance in this group hampers the efficiency of chemical control, alternative control strategies, such as the use of entomopathogenic fungi, are being developed. However, while several studies have focused on the evaluation of the control potential of different fungal species and/or isolates as well as their compatibility with other control methods (e.g., predators or chemical pesticides), knowledge on the extent of inter- and intraspecific variation in spider mite susceptibility to fungal infection is as yet incipient. Here, we measured the mortality induced by two generalist fungi, Beauveria bassiana and Metarhizium brunneum, in 12 spider mite populations belonging to different Tetranychus species: T. evansi, T. ludeni, and T. urticae (green and red form), within a full factorial experiment. We found that spider mite species differed in their susceptibility to infection by both fungal species. Moreover, we also found important intraspecific variation for this trait. These results draw caution on the development of single strains as biocontrol agents. Indeed, the high level of intraspecific variation suggests that (a) the one-size-fits-all strategy may fail to control spider mite populations and (b) hosts resistance to infection may evolve at a rapid pace. Finally, we propose future directions to better understand this system and improve the long-term success of spider mite control strategies based on entomopathogenic fungi.
\end{abstract}

\section{KEYWORDS}

entomopathogenic fungi, host evolution, parasite-induced mortality, resistance,

Tetranychidae, tolerance

\section{INTRODUCTION}

Pesticides are still the main weapon used to control crop pests and disease vectors, despite the major threats they represent for food safety and for the environment (Bourguet \& Guillemaud, 2016). Moreover, the pervasive evolution and rapid spread of resistance to pesticides severely affect their efficiency in many taxa (Casida \& Quistad, 1998). Therefore, alternative control strategies are being

*Zélé and Altıntaş are joint first authors.

This is an open access article under the terms of the Creative Commons Attribution License, which permits use, distribution and reproduction in any medium, provided the original work is properly cited.

(c) 2020 The Authors. Ecology and Evolution published by John Wiley \& Sons Ltd. 
sought to control disease epidemics and outbreaks of agricultural crop pests (Hajek, McManus, \& Delalibera, 2007; Lacey, Frutos, Kaya, \& Vail, 2001; Parolin et al., 2012; Zindel, Gottlieb, \& Aebi, 2011), including spider mites (Attia et al., 2013).

Spider mite of the genus Tetranychus (Acari: Tetranychidae) are ubiquitous major crop pests of c.a. 1,100 plant species belonging to more than 140 different plant families (Migeon \& Dorkeld, 20062017-2017), destroying annual and perennial crops. A few studies have evaluated the economic costs of spider mites, which vary among crops, seasons, and plant age (Alatawi, Margolies, \& Nechols, 2007; Flamini, 2006; Opit, Chen, Williams, Nechols, \& Margolies, 2005; Park \& Lee, 2002, 2005, 2007; Weihrauch, 2005), and theoretical studies suggest that detrimental effects of spider mites in agriculture will dramatically increase with increased global warming (Migeon et al., 2009). Moreover, due to their short generation time and high fecundity, spider mites rapidly develop resistance to pesticides (Van Leeuwen, Vontas, Tsagkarakou, Dermauw, \& Tirry, 2010). Important efforts are thus being developed to evaluate the efficiency of different biological control methods, such as the use of essential oils or natural enemies (e.g., predators, entomopathogenic bacteria, and fungi; Attia et al., 2013). In particular, a plethora of studies have evaluated the virulence of many fungal species (e.g., Neozygites spp., Metarhizium spp., Beauveria bassiana, and Lecanicillium lecanii) and/or strains to identify the best candidates for efficient spider mite control (e.g., Bugeme, Maniania, Knapp, \& Boga, 2008; Chandler, Davidson, \& Jacobson, 2005; Maniania, Bugeme, Wekesa, Delalibera, \& Knapp, 2008; Shi, Zhang, \& Feng, 2008; Shin, Bae, Kim, Yun, \& Woo, 2017), as well as their compatibility with other control methods, such as predatory mites (e.g., Dogan, Hazir, Yildiz, Butt, \& Cakmak, 2017; Seiedy, 2014; Seiedy, Saboori, \& Allahyari, 2012; Seiedy, Saboori, \& Zahedi-Golpayegani, 2013; Ullah \& Lim, 2017; Vergel, Bustos, Rodriguez, \& Cantor, 2011; Wu, Xie, Li, Xu, \& Lei, 2016) or pesticides (e.g., Irigaray, Marco-Mancebon, \& PerezMoreno, 2003; Klingen \& Westrum, 2007; Shi, Jiang, \& Feng, 2005). However, these studies were conducted using a single host population and potential intraspecific variations in spider mites susceptibility have, to our knowledge, never been investigated within a single experiment (but see, for instance: Afifi, Mabrouk, \& Asran, 2010, Fiedler \& Sosnowska, 2007, Ribeiro, Gondim, Calderan, \& Delalibera, 2009 for a comparison among spider mites and/or among other arthropod species; or Milner, 1982, 1985, Perinotto et al., 2012, Uma Devi, Padmavathi, Uma Maheswara Rao, Khan, \& Mohan, 2008 for intraspecific variation within other arthropod species).

Both intra- and interspecific variability in host susceptibility to infection may modify epidemiological patterns of parasite in natural host populations (Dwyer, Elkinton, \& Buonaccorsi, 1997; Hawley \& Altizer, 2011; Read, 1995), thereby altering the efficiency and environmental persistence of biocontrol agents. Moreover, the use of such agents generates a strong selection pressure on the target pests (e.g., Fenner \& Fantini, 1999, see also Tabashnik, 1994, Moscardi, 1999) and, in general, variability in host susceptibility to infection may have important consequences for the evolution of host resistance as well as parasite virulence and transmission (Elena, 2017;
Sorci, Moller, \& Boulinier, 1997; Stevens \& Rizzo, 2008). Hence, assessing both intra- and interspecific variability in spider mite susceptibility to infection by different potential biocontrol agents is a prerequisite for the development of efficient and long-lasting control strategies.

To this aim, we assessed the susceptibility to fungi infection of 12 different spider mite populations belonging to different species that are ubiquitous in Europe and often co-occur in the field (Migeon \& Dorkeld, 2006-2017-2017, Zélé, Santos, Godinho, \& Magalhães, 2018b): three populations of the green form of T. urticae, three populations of the red form of $T$. urticae (also referred to as T. cinnabarinus by some authors; e.g., Shi \& Feng, 2004, Shi et al., 2005, Li, Chen, \& Hong, 2009), three populations of T. ludeni, and three populations of T. evansi. We used two generalist entomopathogenic fungi species, B. bassiana and Metarhizium brunneum, as Beauveria and Metarhizium spp. are among the most used fungi in commercial production (Vega et al., 2009), and have wide geographical and host ranges (Greif \& Currah, 2007; Gurlek, Sevim, Sezgin, \& Sevim, 2018; Meyling \& Eilenberg, 2007; Rehner, 2005; Roberts \& Leger, 2004). We then discuss the possible ecological and evolutionary causes and underlying mechanisms leading to the observed results, as well as their potential consequences for the evolution of both hosts susceptibility to infection and fungi virulence. Finally, we propose future directions to improve long-term success of spider mite control strategies using entomopathogenic fungi.

\section{2 | MATERIALS AND METHODS}

\section{1 | Spider mite populations and rearing}

Twelve populations of Tetranychid mites were used in this study: three of T. evansi (called BR, GH, and QL), three of T. ludeni (called $\mathrm{OBI}$, Alval, and Assaf), three of the red form of T. urticae (called AIRo, AMP.tet, and FR.tet), and three of the green form of T. urticae (called TOM.rif, LS.tet, and B6JS). Most of these populations were collected in Portugal from 2013 to 2016; FR.tet was collected in France and AIRo in Spain in 2013. The population BR of T. evansi was collected in a greenhouse in Brazil in 2002 (Godinho, Janssen, Dias, Cruz, \& Magalhães, 2016; Sarmento et al., 2011), and the population LS.tet of the green form of T. urticae derived from the London strain, which was used to sequence the species genome (Grbic et al., 2011). These populations originated from various plant species in the field, and none of them carried bacterial endosymbionts (i.e., Wolbachia, Cardinium, Rickettsia, Arsenophonus, Spiroplasma), either because they were initially uninfected when collected in the field (Zélé, Santos, Olivieri, et al., 2018a), or following antibiotic treatment (three generations with tetracycline hydrochloride, or one generation with rifampicin; all populations with ".tet" or ".rif" suffix, respectively; Breeuwer, 1997; Gotoh et al., 2005; Li, Floate, Fields, $\&$ Pang, 2014). All the information concerning these populations is summarized in (Table 1). They were subsequently reared in the laboratory under standard conditions $\left(25 \pm 2^{\circ} \mathrm{C}, 60 \% \mathrm{RH}, 16 / 8-\mathrm{hr}\right.$ 


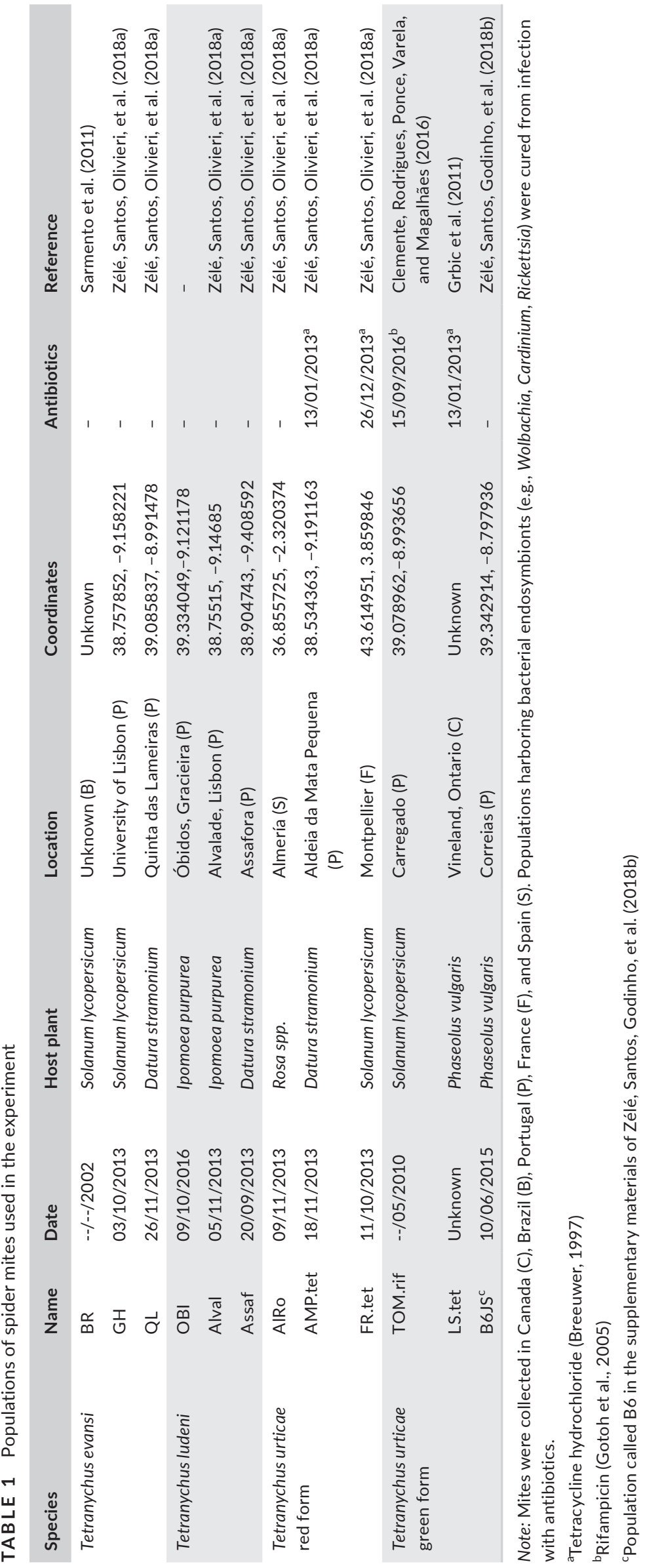


L/D) at high numbers (c.a. 500-1,000 females per cage) in insectproof cages containing either bean cv. Contender seedlings (obtained from Germisem, Oliveira do Hospital, Portugal) for T. urticae and T. Iudeni, or tomato cv. Money Maker seedlings (obtained from Mr. Fothergill's Seeds, Kentford, UK) for T. evansi.

\subsection{Entomopathogenic fungi strains and preparation of inoculum}

We used the strains V275 (=Met52, F52, BIPESCO 5) of M. brunneum and UPH-1103 of B. bassiana , obtained from Swansea University (UK) and from Siedlce University (Poland), respectively, as they were previously shown to have the potential to suppress T. urticae populations (Dogan et al., 2017). The procedures used for fungal growth, inoculum preparation, and spider mite infection are similar to that described in Dogan et al. (2017). Briefly, the two fungi were grown on Sabouraud Dextrose Agar (SDA) medium at $25^{\circ} \mathrm{C}$ for 2 weeks. Conidia were harvested from sporulating cultures with the aid of a spatula, washed with sterile distilled water, and filtered through four layers of gauze to remove any hyphae.

\section{3 | Spider mite infection and survival}

The experiment was conducted in a growth chamber under standard conditions $\left(25 \pm 2^{\circ} \mathrm{C}, 80 \% \mathrm{RH}, 16 / 8-\mathrm{hr}\right.$ L/D). Roughly 2 weeks prior to the experiment, age cohorts were created for each spider mite population by collecting ca. 100 females from each mass culture, allowing them to lay eggs during 4 days on detached bean leaves placed on water-soaked cotton. The offspring from these cohorts was used in the experiment.

One day prior to the onset of this experiment, 20 adult mated females with similar age were randomly collected from each cohort and placed on a $9-\mathrm{cm}^{2}$ bean leaf disk on top of wet cotton (to ensure the leaf remained hydrated) with the abaxial (underside) surface facing upwards. On the first day of the experiment, the surface of the leaf disks was sprayed using a hand sprayer with $2.5 \mathrm{ml}$ of a spore suspension of M. brunneum or B. bassiana in $0.03 \%(v / v)$ aqueous Tween-20 at $1 \times 10^{7}$ conidia/ml, or, as control, with $0.03 \%$ aqueous Tween-20 only. Subsequently, female survival was monitored every $24 \mathrm{hr}$ during 10 days by counting both dead and alive individuals. A total of twelve replicates per infection treatment (sprayed with B. bassiana , with M. brunneum, or with Tween-20 only) per population of each species were performed within seven temporal blocks (roughly three replicates of each treatment per block).

\section{4 | Statistical analysis}

The analyses were carried out using the R statistical package (version 3.5.3). Survival data were analyzed using Cox proportional hazards mixed-effect models (coxme, kinship package). Spider mite species, or populations within each species, and infection treatment (sprayed with B. bassiana , with M. brunneum, or with Tween-20 only as control) were fit in as fixed explanatory variables, whereas disks nested within population, population (in the case of interspecific variation only), and block were fit as random explanatory variables. Hazard ratios (HR) were obtained from these models as an estimate of the difference between the rates of dying (i.e., the instantaneous rate of change in the log number of survivors per unit of time; Crawley, 2007) between the controls of each species/population (by changing the intercept of the model) and the B. bassiana or M. brunneum treatments.

Maximal models, including all higher-order interactions, were simplified to establish a minimal model by sequentially eliminating nonsignificant terms and interactions (Crawley, 2007). The significance of the explanatory variables was established using chi-squared tests (Bolker, 2008). The significant chi-squared values given in the text are for the minimal model, whereas nonsignificant values correspond to those obtained before deletion of the variable from the model.

To further explore significant interactions between species/population and treatment effects on female survival, the two factors were concatenated to fit a single fixed factor containing all species/ population by treatments levels in the models (i.e., 12 levels for species by treatment effects, or 9 levels for population by treatment effects within each species). Multiple comparisons between levels were then performed from these models using general linear hypotheses (glht, package multicomp) with Holm corrections, which uses classical chi-square (Wald test) for testing the global hypothesis $\mathrm{H}_{0}$.

\section{3 | RESULTS}

\section{1 | Interspecific variation of spider mite susceptibility to infection by Beauveria bassiana and Metarhizium brunneum}

The statistical analyses revealed a significant interaction between treatments (females sprayed with either Tween-20 only as control, B. bassiana , or M. brunneum) and species (T. evansi, T. ludeni, red and green form of $T$. urticae $)$ on the survival of spider mites $\left(X^{2}{ }_{6}=80.61\right.$, $p<.001$; Figure 1). Indeed, multiple comparisons of hazard ratios (HRs) revealed that all spider mite species were not equally affected by infection (Figure 1e; Table 2 for the statistical results of all multiple comparisons): Both fungi induced a stronger mortality in T. evansi $(\mathrm{HR}=5.04$ for B. bassiana , and $\mathrm{HR}=5.15$ for M. brunneum) and in the green form of $T$. urticae ( $H R=5.30$ for $B$. bassiana , and $\mathrm{HR}=6.27$ for $M$. brunneum), than in $T$. ludeni $(\mathrm{HR}=3.25$ for B. bassiana , and $\mathrm{HR}=3.73$ for $M$. brunneum) and in the red form of T. urticae ( $\mathrm{HR}=3.84$ for $B$. bassiana , and $\mathrm{HR}=3.21$ for M. brunneum). Moreover, while the two fungi induced similar mortality in T. evansi and in T. ludeni, infection with B. bassiana led to higher mortality than M. brunneum in the red form of T. urticae, while the reverse was found in the green form of T. urticae. Note, however, that survival in the T. evansi control was higher than in that of the three other species (Figure 1d and Table 2). 

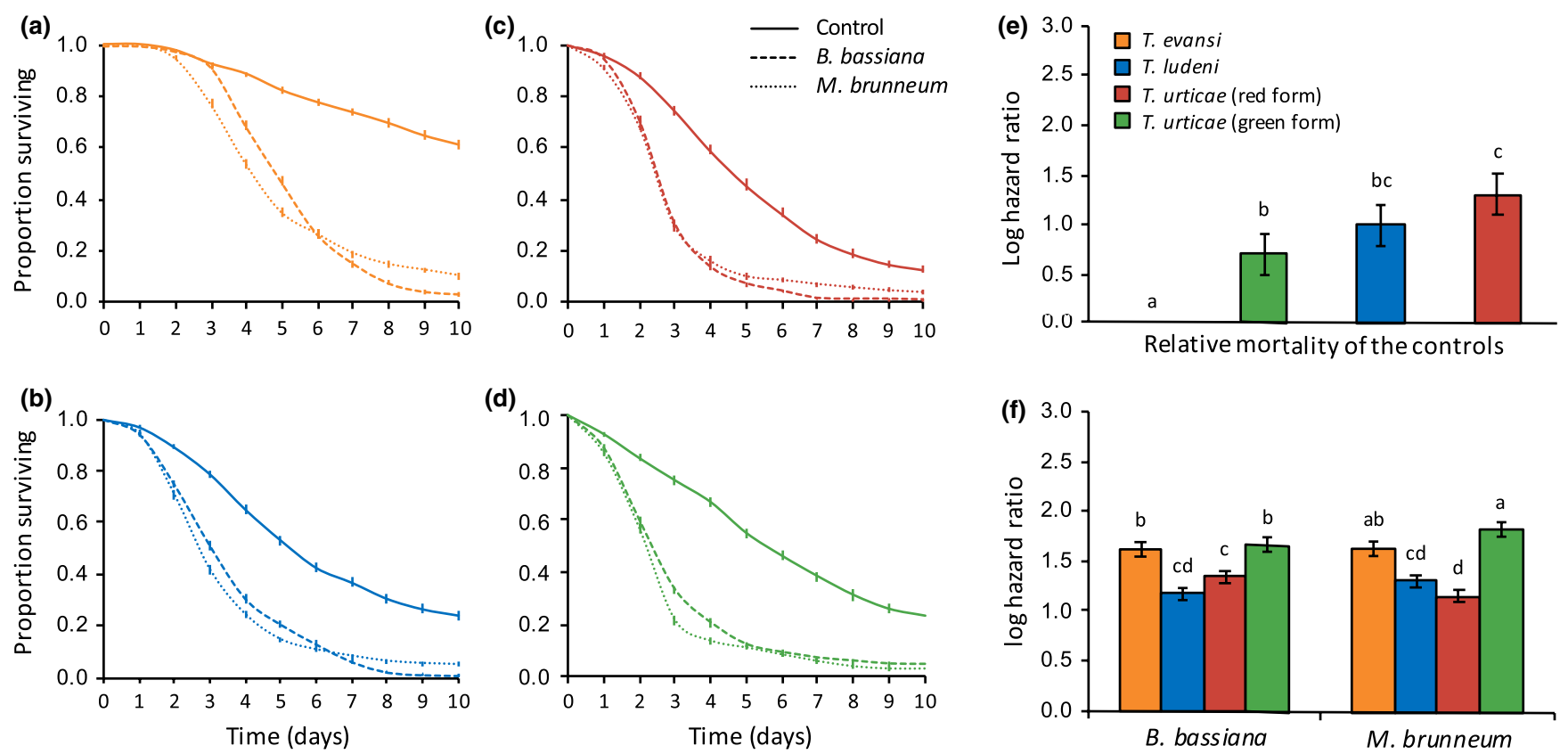

FIGURE 1 Survival curves of spider mite females (proportion surviving \pm SE) from (a) Tetranychus evansi, (b) Tetranychus ludeni, (c) red form of Tetranychus urticae, and (d) green form of T. urticae, sprayed with Beauveria bassiana (dashed lines), Metarhizium brunneum (dotted lines), or with Tween-20 only (control; solid lines). (e) Estimated mortality of the controls (sprayed with Tween-20 only) of each spider mite species relative to the control of T. evansi (log hazard ratio $\pm S E$ ). (f) Estimated mortality of each spider mite species upon infection by each fungus relative to their respective control (log hazard ratio $\pm S E$ ); identical letter superscripts indicate nonsignificant differences between treatments at the $5 \%$ level (multiple comparisons with Holm correction)

\section{2 | Intraspecific variation of spider mite susceptibility to infection by Beauveria bassiana and Metarhizium brunneum}

We also found a statistically significant interaction between infection treatment and population on spider mite survival within each of the species studied (in the green form of T. urticae: $X^{2}{ }_{4}=79.60$, $p<.0001$; Figure 2; in the red form T. urticae: $X^{2}{ }_{4}=12.12, p<.02$; Figure 3; in T. ludeni: $X^{2}{ }_{4}=17.41, p<.002$; Figure 4; in T. evansi: $X_{4}^{2}=106.72, p<.0001$; Figure 5). Indeed, although the two fungi induced a similar mortality in most populations within each species (e.g., the populations LS.tet, FR.tet, AIRo, OBI, Assaf, and all populations of T. evansi; see Table 3 for the statistical results of all comparisons), B. bassiana induced a higher mortality than M. brunneum in the populations TOM.rif and AMP.tet (green and red form of T. urticae, respectively); and the reverse was found in the populations B6JS and Alval (green form of T. urticae and T. ludeni, respectively). Moreover, although the susceptibility to infection was relatively similar between populations of the red form of T. urticae (Figure 3e) and in T. ludeni (Figure 4e), we found important variation between populations of the green form of T. urticae (Figure 2e) and in T. evansi (Figure 5e). In the green form of T. urticae, B. bassiana induced a higher mortality in the populations TOM.rif and B6JS ( $H R=6.01$ and $H R=4.41$, respectively) than in the population LS.tet $(H R=2.85$; Figure 2e; Table 3a). Similarly, M. brunneum induced higher mortality in B6JS (HR = 8.67) than in TOM.rif ( $\mathrm{HR}=4.60)$, and the lowest mortality was found in LS.tet $(H R=3.04$; Figure 2e; Table 3a). In
T. evansi, both fungi species induced a higher mortality in the populations $\mathrm{GH}$ and $\mathrm{BR}$ than in the population $\mathrm{QL}(\mathrm{HR}=12.13, \mathrm{HR}=10.25$, and $H R=2.77$ in average, respectively; Figure 5e; Table 3d). Note, however, that QL control had a much lower survival than that of the two other populations (Figure $5 \mathrm{~d}$; Table $3 \mathrm{~d}$ ).

\section{4 | DISCUSSION}

In this study, we found both intra- and interspecific variability in the susceptibility of Tetranychus spider mite to infection by B. bassiana and M. brunneum. Overall, we observed a higher mortality upon infection in T. evansi and in the green form of T. urticae, than in T. ludeni and in the red form of T. urticae. These results, however, may not reflect accurately the virulence of both fungi in each of these spider mite species. Indeed, we further found important variation among populations within each species. Most variation was found among populations of T. evansi and of the green form of T. urticae, with, for instance, the mortality upon infection of two populations of T. evansi (BR and $\mathrm{GH}$ ) being 5 times higher than that of another (QL). We also found variation among populations of T. ludeni and of the red form of T. urticae, although the amplitude of these effects was relatively smaller and depended on the fungal species.

Overall, our results suggest that spider mite susceptibility to infection is not a phylogenetically conserved trait, and further corroborate the generalist status of both fungal species (Meyling \& Eilenberg, 2007; Rehner, 2005; Roberts \& Leger, 2004). For instance, 


\begin{tabular}{|lllllc}
\hline Type of comparison & Species_treatments & & & & \\
\hline Between controls & compared & Estimate & SE & z value & $p$-value \\
& Te_C versus TuG_C & -0.710 & 0.204 & -3.472 & $.008^{* *}$ \\
& TuG_C versus TI_C & -0.288 & 0.202 & -1.427 & .768 \\
& TI_C versus TuR_C & -0.303 & 0.196 & -1.541 & .740 \\
& TuG_C versus TuR_C & -0.590 & 0.201 & -2.934 & $.040^{*}$ \\
\hline Between species & TuG_BB versus Te_BB & 0.051 & 0.097 & 0.523 & 1.000 \\
sprayed with & TuR_BB versus Te_BB & -2.272 & 0.095 & -2.866 & $.046^{*}$ \\
B. bassiana & TuR_BB versus TI_BB & 0.166 & 0.086 & 1.927 & .432 \\
\hline Between species & TuG_MB versus Te_MB & 0.196 & 0.097 & 2.011 & .399 \\
sprayed with & TI_MB versus Te_MB & -0.323 & 0.097 & -3.337 & $.013^{*}$ \\
M. brunneum & TuR_MB versus TI_MB & -0.149 & 0.088 & -1.695 & .630 \\
\hline Between fungi within & Te_BB versus Te_MB & -0.022 & 0.056 & -0.391 & 1.000 \\
or among species & TI_BB versus TI_MB & -0.137 & 0.055 & -2.481 & .131 \\
& TuR_BB versus & 0.179 & 0.057 & 3.128 & $.025^{*}$ \\
& TuR_MB & & & & \\
\hline & TuG_BB versus & -0.167 & 0.056 & -2.961 & $.040^{*}$ \\
& TuG_MB & & & & \\
\hline & TuG_BB versus Te_MB & 0.029 & 0.097 & 0.296 & 1.000 \\
& TI_BB versus TuR_MB & 0.013 & 0.087 & 0.148 & 1.000 \\
\hline
\end{tabular}

TABLE 2 Results of multiple comparisons (with Holm correction) between hazard ratios obtained for different spider mite species (Te: Tetranychus evansi; TI: Tetranychus ludeni; TuR: red form of Tetranychus urticae; TuG: green form of Tetranychus urticae) among the different treatments (BB: Beauveria bassiana; MB: Metarhizium brunneum; C: Control)

Note: Hazard ratios of infection by each fungus were estimated relative to the control within each species.

${ }^{*} p$-value $<.05,{ }^{* *} p$-value $<.01,{ }^{* * *} p$-value $<.001$.
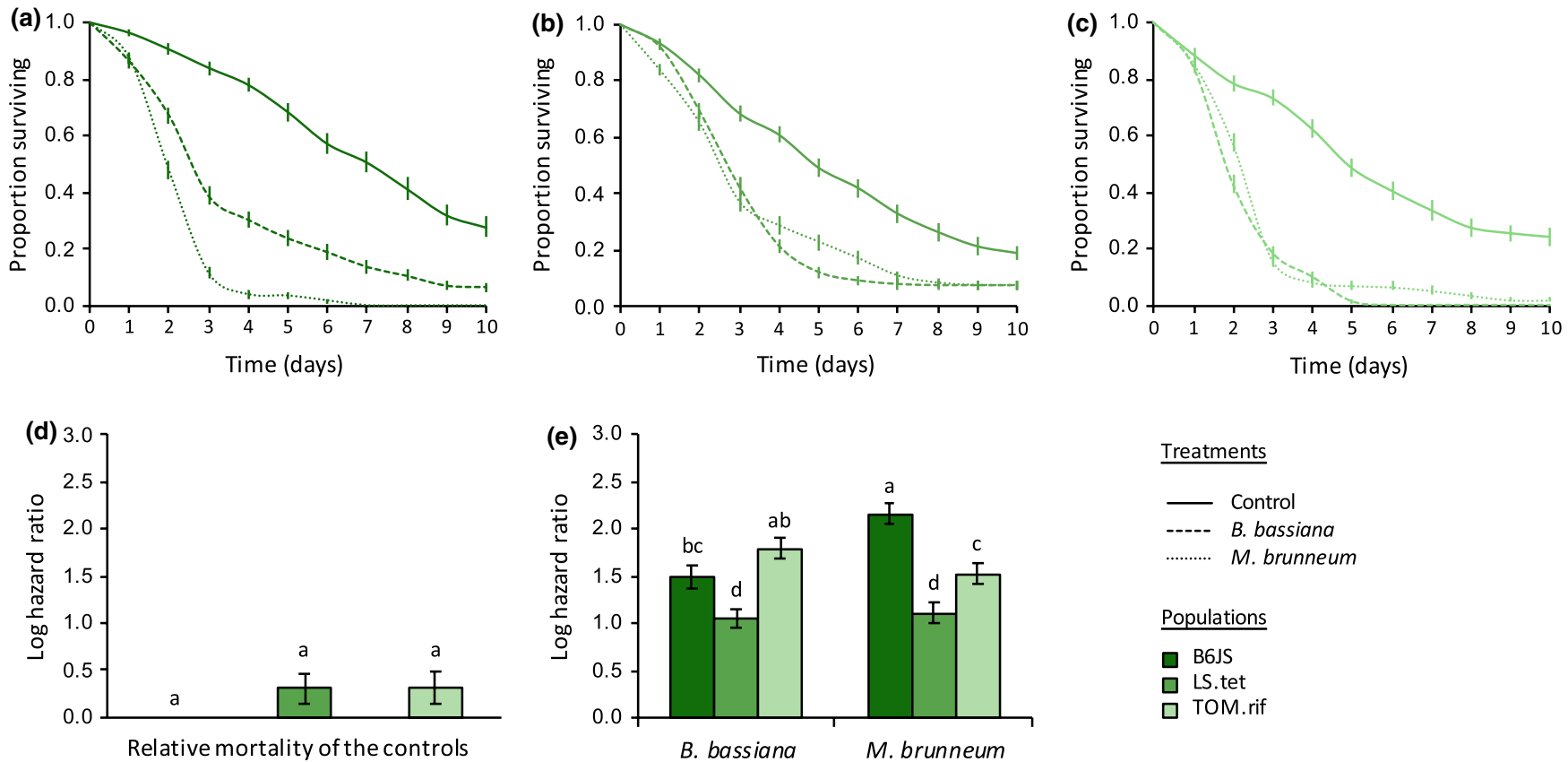

$\underline{\text { Treatments }}$

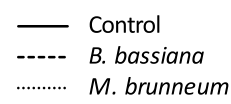

Populations

$\square$ B6JS

$\square$ LS.tet

$\square$ TOM.rif

FIGURE 2 Survival curves of spider mite females (proportion surviving \pm SE) from different populations of the green form of Tetranychus urticae: (a) B6JS, (b) LS.tet, and (c) TOM.rif, sprayed with Beauveria bassiana (dashed lines), Metarhizium brunneum (dotted lines), or with Tween-20 only (control; solid lines). (d) Estimated mortality of the controls (sprayed with Tween-20 only) of each spider mite population relative to the control of the population B6JS (log hazard ratio $\pm S E$ ). (e) Estimated mortality of each spider mite population upon infection by each fungus relative to their respective control (log hazard ratio $\pm S E$ ); identical letter superscripts indicate nonsignificant differences between treatments at the $5 \%$ level (multiple comparisons with Holm correction) 

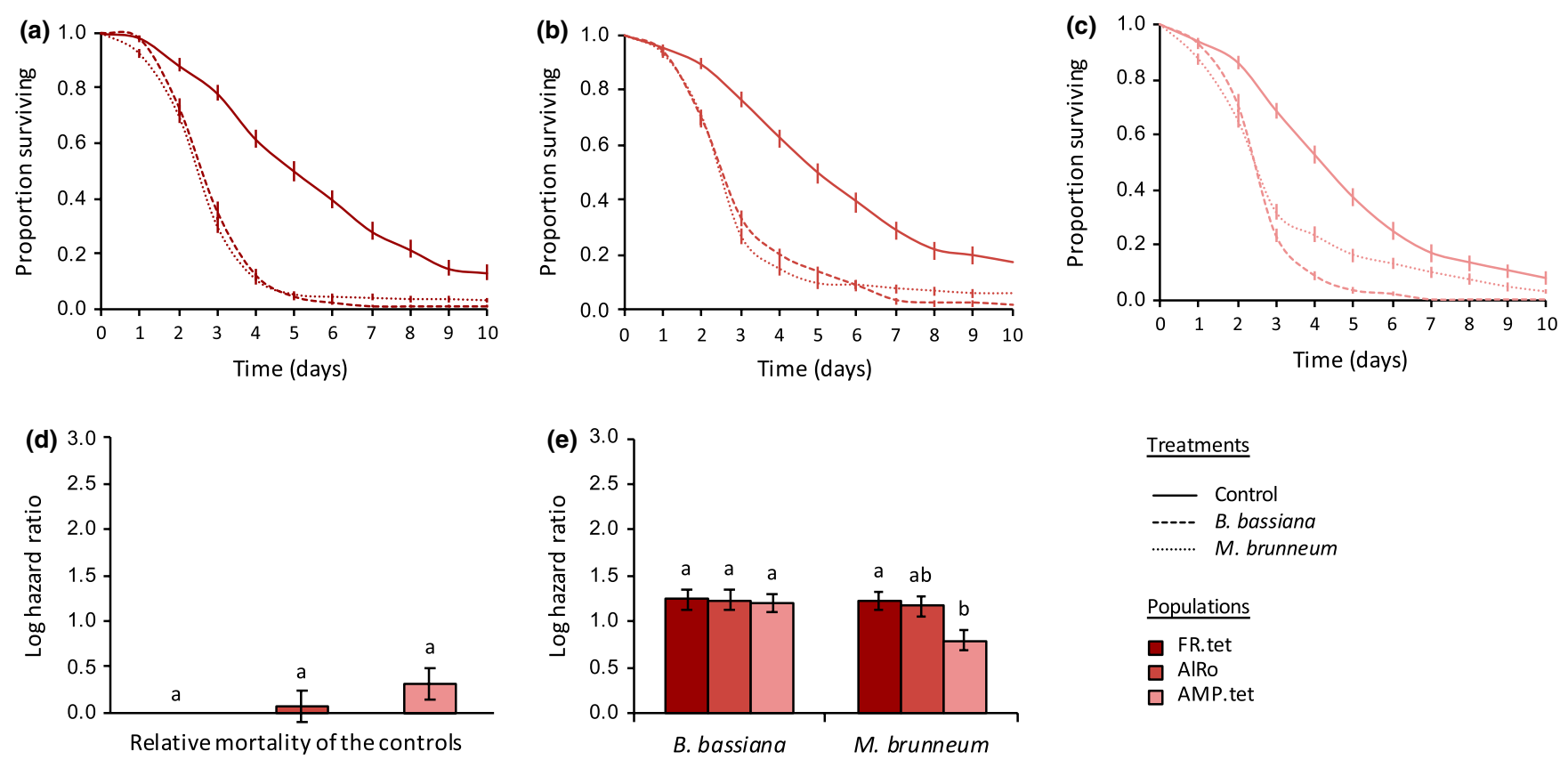

Treatments

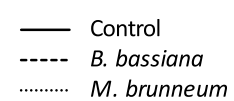

Populations

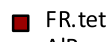

$\square$ AlRo

$\square$ AMP.tet

FIGURE 3 Survival curves of spider mite females (proportion surviving \pm SE) from different populations of the red form of Tetranychus urticae: (a) FR.tet, (b) AIRo, and (c) AMP.tet, sprayed with Beauveria bassiana (dashed lines), Metarhizium brunneum (dotted lines), or with Tween-20 only (control; solid lines). (d) Estimated mortality of the controls (sprayed with Tween-20 only) of each spider mite population relative to the control of the population FR.tet (log hazard ratio $\pm S E$ ). (e) Estimated mortality of each spider mite population upon infection by each fungus relative to their respective control (log hazard ratio $\pm S E$ ); identical letter superscripts indicate nonsignificant differences between treatments at the $5 \%$ level (multiple comparisons with Holm correction)
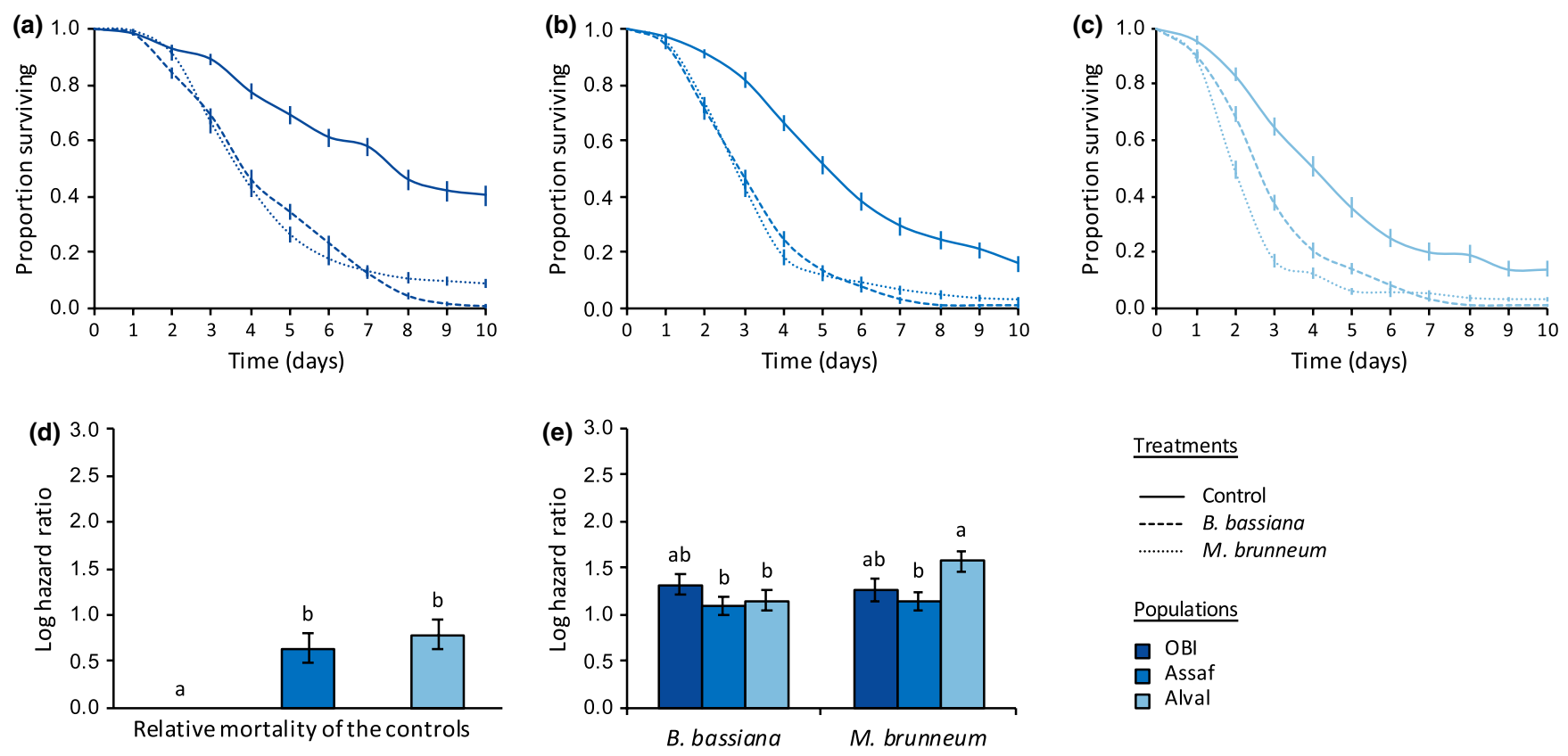

$\underline{\text { Treatments }}$

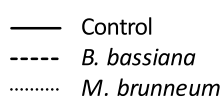

Populations

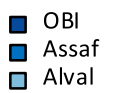

FIGURE 4 Survival curves of spider mite females (proportion surviving \pm SE) from different Tetranychus ludeni populations: (a) OBI, (b) Assaf, and (c) Alval, sprayed with Beauveria bassiana (dashed lines), Metarhizium brunneum (dotted lines), or with Tween-20 only (control; solid lines). (d) Estimated mortality of the controls (sprayed with Tween-20 only) of each spider mite population relative to the control of the population $\mathrm{OBI}(\log$ hazard ratio $\pm S E$ ). (e) Estimated mortality of each spider mite population upon infection by each fungus relative to their respective control (log hazard ratio $\pm S E$ ); identical letter superscripts indicate nonsignificant differences between treatments at the $5 \%$ level (multiple comparisons with Holm correction)

B. bassiana occurs naturally in more than 700 host species (Inglis, Goettel, Butt, \& Strasser, 2001), and this range is likely underestimated as prevalence estimates are usually done in arthropod species that are crop pests or predators and parasitoids used as biocontrol agents (Meyling \& Eilenberg, 2007). Moreover, differences in virulence between the two fungi shown here suggest population-specific 

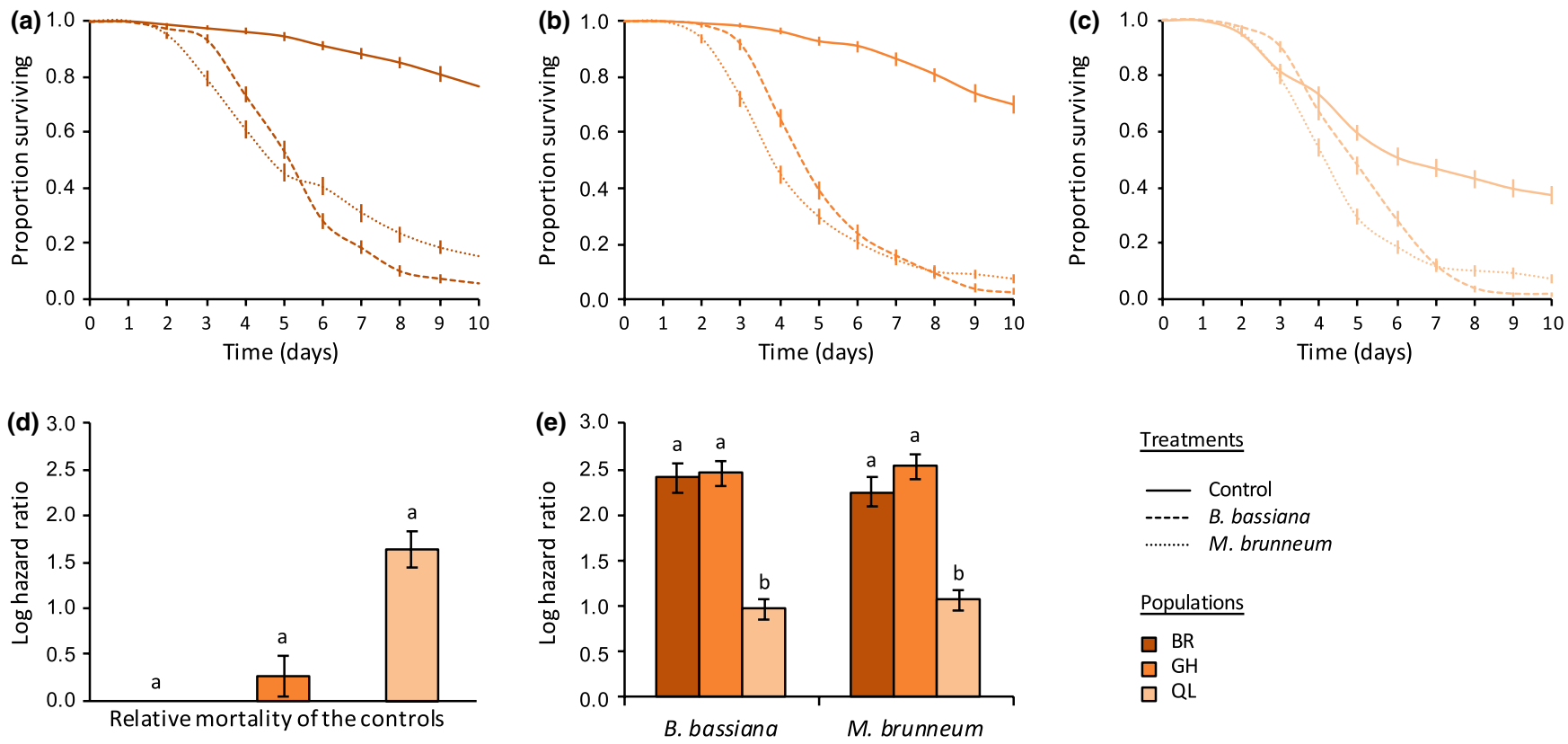

FIGURE 5 Survival curves of spider mite females (proportion surviving \pm SE) from different Tetranychus evansi populations: (a) BR, (b) GH, and (c) QL, sprayed with Beauveria bassiana (dashed lines), Metarhizium brunneum (dotted lines), or with Tween-20 only (control; solid lines). (d) Estimated mortality of the controls (sprayed with Tween-20 only) of each spider mite population relative to the control of the population BR (log hazard ratio $\pm S E$ ). (e) Estimated mortality of each spider mite population upon infection by each fungus relative to their respective control (log hazard ratio $\pm S E$ ); identical letter superscripts indicate nonsignificant differences between treatments at the $5 \%$ level (multiple comparisons with Holm correction)

responses to each fungus, instead of a more general response against infection. For instance, M. brunneum is more virulent than B. bassiana in the population B6JS of green T. urticae and in the population Alval of T. ludeni, while the reverse occurred in the population AMP. tet of the red form of T. urticae. Such differences in susceptibility to infection between populations independently of their phylogenetic relationship may thus reflect differences in exposure by each fungus species (i.e., different selection pressure for resistance mechanisms to evolve) throughout their evolutionary history.

Variations in the prevalence of each fungus leading to different exposure may, for instance, occur between different geographical areas due to several environmental factors, such as temperature, humidity, and solar (UV) irradiation (Meyling \& Eilenberg, 2007). However, these fungi are known to have a cosmopolitan distribution, and our results show no clear association between the susceptibility of a particular spider mite population and its country of origin. For instance, the T. evansi populations BR and GH come from Brazil and Portugal, respectively, but do not differ in susceptibility to infection by both fungi; similarly, the effect of B. bassiana does not differ between populations of red T. urticae collected in France (FR.tet), Spain (AIRo), and Portugal (AMP.tet). Instead, we found different susceptibility to infection between populations at small geographical scales, such as in the T. evansi populations GH and QL and in the green T. urticae populations B6JS and TOM.rif upon infection by both fungi or in the T. Iudeni populations Assaf and Alval upon infection by M. brunneum, while all of these populations were collected in the same region in Portugal. These results might thus be explained by microhabitats-specific distribution of the fungi, as previously found for different isolates of B. bassiana (e.g., Ormond, Thomas, Pugh, Pell, \& Roy, 2010; Wang, Shah, Patel, Li, \& Butt, 2003). Moreover, several studies suggest that both B. bassiana and Metarhizium spp. have the potential to interact directly with the host plants of arthropods (reviewed in Meyling \& Eilenberg, 2007), which may potentially lead to plant-specific distribution of the fungi. Indeed, Metarhizium spp. occur in the rhizosphere, which possibly provides a "refuge" where the fungus can survive outside insect hosts, and the presence of $B$. bassiana in internal plant tissue has been discussed as an adaptive protection against herbivorous insects (reviewed in Meyling \& Eilenberg, 2007). However, the host plant range of these fungi is, to our knowledge, as yet unknown. Moreover, no field survey of these fungi has been conducted to date in Tetranychus spp. (but see, for instance, Dick \& Buschman, 1995, Van Der Geest, Moraes, Navia, \& Tanzini, 2002, for other fungi and/or spider mite species, Debnath \& Sreerama Kumar, 2017). Future evaluation of the prevalence of infection by M. brunneum and $B$. bassiana in natural populations of spider mites collected on different host plants would thus be necessary to further understand possible factors that could explain the patterns observed in our experiment (Boots, Best, Miller, \& White, 2009).

Decreased host susceptibility to infection may be the result of two different (albeit nonexclusive) mechanisms (Boots et al., 2009; Read, Graham, \& Raberg, 2008): resistance (i.e., reduction in parasite load) and/or tolerance (i.e., reduction of the damage incurred by a parasite). Differential host resistance to fungal infection might be due, for instance, to variability in different cuticular barriers. Such 
TAB LE 3 Results of the multiple comparisons (with Holm correction) between hazard ratios obtained for different populations of (a) the green form of Tetranychus urticae, (b) the red form of Tetranychus urticae, (c) Tetranychus ludeni, and (d) Tetranychus evansi among the different treatments (BB: Beauveria bassiana; MB: Metarhizium brunneum; C: control)

\begin{tabular}{|c|c|c|c|c|c|}
\hline Type of comparison & Populations_treatments compared & Estimate & SE & $z$ value & $p$-value \\
\hline \multirow[t]{2}{*}{ Between controls } & TOM.rif_C versus LS.tet_C & -0.002 & 0.127 & -0.018 & 1.000 \\
\hline & B6JS_C versus TOM.rif_C & -0.305 & 0.169 & -1.809 & .312 \\
\hline $\begin{array}{l}\text { Between populations sprayed with } \\
\text { B. bassiana }\end{array}$ & B6JS_BB versus TOM.rif_BB & -0.302 & 0.156 & -1.981 & .285 \\
\hline \multirow{2}{*}{$\begin{array}{l}\text { Between populations sprayed with } \\
\text { M. brunneum }\end{array}$} & B6JS_MB versus TOM.rif_MB & 0.634 & 0.154 & 4.118 & $<.0005^{* * *}$ \\
\hline & TOM.rif_MB versus LS.tet_MB & 0.414 & 0.147 & 2.816 & $.044^{*}$ \\
\hline \multirow{2}{*}{$\begin{array}{l}\text { Between fungi within or among } \\
\text { populations }\end{array}$} & TOM.rif_BB versus TOM.rif_MB & 0.268 & 0.093 & 2.868 & $.041^{*}$ \\
\hline & LS.tet_BB versus LS.tet_MB & -0.065 & 0.096 & -0.671 & 1.000 \\
\hline \multicolumn{6}{|c|}{ (b) Multiple comparisons between populations of the red form of T. urticae } \\
\hline \multirow[t]{3}{*}{ Between controls } & AIRo_C versus AMP.tet_C & -0.244 & 0.151 & -1.621 & .841 \\
\hline & AMP.tet_C versus FR.tet_C & 0.309 & 0.162 & 1.903 & .513 \\
\hline & FR.tet_C versus AIRo_C & -0.065 & 0.161 & -0.404 & 1.000 \\
\hline \multirow{3}{*}{$\begin{array}{l}\text { Between populations sprayed with } \\
\text { B. bassiana }\end{array}$} & AIRo_BB versus FR.tet_BB & -0.011 & 0.149 & -0.072 & 1.000 \\
\hline & AlRo_BB versus AMP.tet_BB & 0.037 & 0.147 & 0.248 & 1.000 \\
\hline & FR.tet_BB versus AMP.tet_BB & 0.047 & 0.146 & 0.324 & 1.000 \\
\hline \multirow{2}{*}{$\begin{array}{l}\text { Between populations sprayed with } \\
\text { M. brunneum }\end{array}$} & AIRo_MB versus FR.tet_MB & -0.062 & 0.148 & -0.416 & 1.000 \\
\hline & AIRo_MB versus AMP.tet_MB & 0.375 & 0.154 & 2.431 & .151 \\
\hline \multirow{2}{*}{ Between controls } & Alval_C versus Alval_C & -0.141 & 0.144 & -0.980 & 1.000 \\
\hline & $\mathrm{OBI} C \mathrm{C}$ versus $\mathrm{OBI} \_\mathrm{C}$ & 0.780 & 0.158 & 4.945 & $9.91 \mathrm{e}-06^{* * *}$ \\
\hline \multirow{3}{*}{$\begin{array}{l}\text { Between populations sprayed with } \\
\text { B. bassiana }\end{array}$} & Assaf_BB versus Assaf_BB & 0.237 & 0.150 & 1.581 & .867 \\
\hline & Alval_BB versus Alval_BB & 0.171 & 0.155 & 1.101 & 1.000 \\
\hline & OBI_BB versus $\mathrm{OBI} \_\mathrm{BB}$ & 0.066 & 0.147 & 0.447 & 1.000 \\
\hline \multirow{3}{*}{$\begin{array}{l}\text { Between populations sprayed with } \\
\text { M. brunneum }\end{array}$} & Assaf_MB versus Assaf_MB & 0.113 & 0.153 & 0.738 & 1.000 \\
\hline & Alval_MB versus Alval_MB & -0.315 & 0.159 & -1.983 & .426 \\
\hline & $\mathrm{OBI} M \mathrm{MB}$ versus $\mathrm{OBI} \_\mathrm{MB}$ & 0.428 & 0.150 & 2.858 & $.043^{*}$ \\
\hline \multirow{4}{*}{$\begin{array}{l}\text { Between fungi within or among } \\
\text { populations }\end{array}$} & $\mathrm{OBI}$-MB versus OBI_MB & 0.062 & 0.096 & 0.645 & 1.000 \\
\hline & Assaf_MB versus Assaf_MB & -0.062 & 0.094 & -0.654 & 1.000 \\
\hline & Alval_MB versus Alval_MB & -0.424 & 0.095 & -4.469 & $9.42 \mathrm{e}-05^{* * *}$ \\
\hline & Alval_MB versus Alval_MB & -0.253 & 0.157 & -1.606 & .867 \\
\hline
\end{tabular}

(d) Multiple comparisons between populations of T. evansi 
TABLE 3 (Continued)

\begin{tabular}{|c|c|c|c|c|c|}
\hline Type of comparison & Populations_treatments compared & Estimate & SE & $z$ value & $p$-value \\
\hline \multirow{2}{*}{ Between controls } & $\mathrm{GH}_{-} \mathrm{C}$ versus $\mathrm{QL} \_\mathrm{C}$ & -1.370 & 0.189 & -7.236 & $3.70 e-12^{* * *}$ \\
\hline & QL_C versus BR_C & 1.633 & 0.201 & 8.145 & $4.44 \mathrm{e}-15^{* * *}$ \\
\hline \multirow{2}{*}{$\begin{array}{l}\text { Between populations sprayed with } \\
\text { B. bassiana }\end{array}$} & BR_BB versus $\mathrm{GH}_{-} \mathrm{BB}$ & 0.207 & 0.207 & -0.254 & .914 \\
\hline & BR_BB versus $Q L_{-} B B$ & 1.435 & 0.188 & 7.631 & $2.10 \mathrm{e}-13^{* * *}$ \\
\hline $\begin{array}{l}\text { Between populations sprayed with } \\
\text { M. brunneum }\end{array}$ & BR_MB versus $Q L_{-} M B$ & 1.176 & 0.192 & 6.117 & $6.68 e^{-9 * * *}$ \\
\hline \multirow{3}{*}{$\begin{array}{l}\text { Between fungi within or among } \\
\text { populations }\end{array}$} & BR_BB versus BR_MB & 0.161 & 0.104 & 1.556 & .718 \\
\hline & $\mathrm{GH}_{-} \mathrm{BB}$ versus $\mathrm{GH}_{-} \mathrm{MB}$ & -0.075 & 0.097 & -0.775 & .914 \\
\hline & QL_BB versus $Q L_{-} M B$ & -0.098 & 0.094 & -1.039 & .914 \\
\hline
\end{tabular}

Note: Hazard ratios of infection by each fungus were estimated relative to the control within each population.

${ }^{*} p$-value $<.05,{ }^{* *} p$-value $<.01,{ }^{* * *} p$-value $<.001$.

barriers include the absence of factors necessary for parasite recognition, or the presence of inhibitory compounds (phenols, quinones, and lipids) on the cuticle surface, but also the cuticle thickness, its degree of hardening by sclerotization, its resistance to enzymatic degradation, and its permeability (reviewed in Hajek \& St. Leger, 1994). Subsequently, when a fungus bypass cuticular barriers, variability in systemic immunity may also lead to differential host resistance responses. This may include differential activation of the Toll and JAK/ STAT pathways, which converge into the transcriptional activation of genes involved in phagocytosis, encapsulation, and humoral responses (e.g., Dong, Morton, Ramirez, Souza-Neto, \& Dimopoulos, 2012). Interestingly, several, but not all, important genes described in these pathways in Drosophila melanosgaster were absent in the genome of the green form of T. urticae (Grbic et al., 2011), and spider mites have high mortality upon bacterial infection (Santos-Matos et al., 2017). Whether the presence of such immune genes varies between or within spider mite species and whether their expression depends on different fungal species have not been explored to date. In particular, the absence of many important immune genes in T. urticae suggests that tolerance mechanisms (e.g., via a decrease of the immune response to avoid autophagy) rather than resistance have been favored throughout their evolutionary history. However, such hypothesis remains to be tested and further studies are necessary to better understand the mechanisms of spider mite resistance and tolerance against fungal infection.

Independently of the underlying mechanisms at play, whether spider mite populations differ in resistance or tolerance to fungal infection may have different epidemiological and evolutionary consequences, and, hence, different implications for the long-term success of spider mite control. On the one hand, resistance to infection might be rapidly selected following application of fungi to crops and subsequently invade spider mite populations, thereby decreasing fungi prevalence and hampering the success of such control strategy. On the other hand, host tolerance should have neutral or even positive effect on parasite prevalence (Boots et al., 2009; Miller, White, \& Boots, 2006; Read et al., 2008), but as, by definition, tolerance minimizes the harm caused by pathogens, it may hamper the efficiency of fungi in controlling spider mites. Moreover, host resistance and tolerance may lead to different evolutionary outcomes for parasite virulence (Boots et al., 2009). Indeed, whereas host resistance is predicted to select for increased parasite virulence (e.g., Gandon \& Michalakis, 2000), host tolerance does not reduce parasite fitness and, therefore, will not lead to antagonistic counter-adaptation by pathogens (Raberg, Sim, \& Read, 2007; Rausher, 2001). Still, depending on the nature of the tolerance mechanism, it may lead to the evolution of more virulent and transmissible parasites (Miller et al., 2006), with potentially serious implications for nontolerant populations (Boots et al., 2009), including nontarget species such as crop auxiliaries or spider mite predators. Finally, although increased mortality due to infection should lead to a reduction in oviposition duration, spider mites may evolve the ability to compensate infection-driven fitness costs by changing the timing of their reproductive efforts (i.e., "fecundity compensation"; Parker, Barribeau, Laughton, Roode, \& Gerardo, 2011; Vezilier, Nicot, Gandon, \& Rivero, 2015), thereby limiting the efficiency of fungi applications for population control. Hence, assessing which of these evolutionary outcomes is more likely is timely. In particular, it is likely that the level of intraspecific variation in susceptibility to infection found in our study is recapitulated within populations and is, at least partly, genetically determined. If this is the case, then this trait may evolve at a rapid pace.

In conclusion, our results show both intra- and interspecific variability in spider mite susceptibility to fungi-induced mortality using two generalist fungi, B. bassiana and M. brunneum. To our knowledge, this is the first study investigating the effect of entomopathogenic fungi on the survival of multiple spider mite populations belonging to different species within a single full factorial experiment. In line with laboratory virulence tests that are not necessarily well correlated with field effectiveness (Roberts \& Leger, 2004), our results highlight the importance of studying several host populations/genomes when assessing the efficiency of a given biocontrol agent. These results also draw caution on 
the development of single strains as biocontrol agents, as hosts resistance to infection may evolve at a rapid pace.

\section{ACKNOWLEDGMENTS}

We thank Diogo Godinho and Miguel Cruz for their help in some parts of the experiment, as well as Marta Palma for technical support. We also thank all members of the SM laboratory for useful discussions and suggestions. This work was funded by an FCT-Tubitak agreement (FCT-TUBITAK/0001/2014 and TUBITAK TOVAG 1150610) to IC and SM, by the cE3c FCT Unit UID/BIA/00329/2020 to FZ and SM, and by Adnan Menderes University Research Foundation (ZRF-17055) to IC. FZ was funded through an FCT Post-Doc fellowship (SFRH/BPD/125020/2016). Funding agencies did not participate in the design or analysis of experiments.

\section{CONFLICT OF INTEREST}

None declared.

\section{AUTHOR CONTRIBUTIONS}

$\mathrm{FZ}$ and SM conceived and designed the experiment. IS was involved in the maintenance of spider mite populations and plants. MA acquired the data. FZ performed the statistical analysis. FZ and SM wrote the manuscript, with input from all authors. IC and SM funded the study. All authors have read and approved the final version of the manuscript.

\section{DATA AVAILABILITY STATEMENT}

Full dataset has been deposited in the Dryad Data Repository (https ://doi.org/10.5061/dryad.gmsbcc2j4).

\section{ORCID}

Flore Zélé iD https://orcid.org/0000-0003-2954-5488

Sara Magalhães iD https://orcid.org/0000-0002-8609-7768

\section{REFERENCES}

Afifi, A.-A.-M., Mabrouk, A. M., \& Asran, A. A. (2010). Effect of the entomopathogenic fungus Beauveria bassiana on three acarine pests. In M. Sabelis, \& J. Bruin (Eds.), Trends in acarology (pp. 439-440). Dordrecht, Netherlands: Springer.

Alatawi, F. J., Margolies, D. C., \& Nechols, J. R. (2007). Aesthetic damage thresholds for twospotted spider mites (Acari: Tetranychidae) on impatiens: Effect of plant age and level of infestation. Journal of Economic Entomology, 100, 1904-1909. https://doi.org/10.1093/ jee/100.6.1904

Attia, S., Grissa, K. L., Lognay, G., Bitume, E., Hance, T., \& Mailleux, A. C. (2013). A review of the major biological approaches to control the worldwide pest Tetranychus urticae (Acari: Tetranychidae) with special reference to natural pesticides biological approaches to control Tetranychus urticae. Journal of Pest Science, 86, 361-386. https://doi. org/10.1007/s10340-013-0503-0

Bolker, B. M. (2008). Ecological models and data in R. Princeton, NJ: Princeton University Press.

Boots, M., Best, A., Miller, M. R., \& White, A. (2009). The role of ecological feedbacks in the evolution of host defence: What does theory tell us? Philosophical Transactions of the Royal Society B-Biological Sciences, 364, 27-36. https://doi.org/10.1098/rstb.2008.0160
Bourguet, D., \& Guillemaud, T. (2016). The hidden and external costs of pesticide use. In E. Lichtfouse (Ed.), Sustainable agriculture reviews (Vol. 19, pp. 35-120). Cham, Switzerland: Springer International Publishing.

Breeuwer, J. A. J. (1997). Wolbachia and cytoplasmic incompatibility in the spider mites Tetranychus urticae and T. turkestani. Heredity, 79, 41-47. https://doi.org/10.1038/hdy.1997.121

Bugeme, D. M., Maniania, N. K., Knapp, M., \& Boga, H. I. (2008). Effect of temperature on virulence of Beauveria bassiana and Metarhizium anisopliae isolates to Tetranychus evansi. Experimental and Applied Acarology, 46, 275-285. https://doi.org/10.1007/s10493-008-9179-1

Casida, J. E., \& Quistad, G. B. (1998). Golden age of insecticide research: Past, present, or future? Annual Review of Entomology, 43, 1-16. https ://doi.org/10.1146/annurev.ento.43.1.1

Chandler, D., Davidson, G., \& Jacobson, R. J. (2005). Laboratory and glasshouse evaluation of entomopathogenic fungi against the two-spotted spider mite, Tetranychus urticae (Acari: Tetranychidae), on tomato, Lycopersicon esculentum. Biocontrol Science and Technology, 15, 37-54.

Clemente, S. H., Rodrigues, L. R., Ponce, R., Varela, S. A. M., \& Magalhães, S. (2016). Incomplete species recognition entails few costs in spider mites, despite first-male precedence. Behavioral Ecology and Sociobiology, 70, 1161-1170. https://doi.org/10.1007/ s00265-016-2124-0

Crawley, M. J. (2007). The R Book. Chichester, UK: John Wiley \& Sons Ltd.

Debnath, S., \& Sreerama Kumar, P. (2017). Fungi associated with mortality of the red spider mite, Oligonychus coffeae Nietner (Acari: Tetranychidae), a serious pest of tea in North-Eastern India. Egyptian Journal of Biological Pest Control, 27, 79-83.

Dick, G. L., \& Buschman, L. L. (1995). Seasonal occurrence of a fungal pathogen, Neozygites adjarica (Entomophthorales: Neozygitaceae), infecting banks grass mites, Oligonychus pratensis, and twospotted spider mites, Tetranychus urticae (Acari: Tetranychidae), in field corn. Journal of the Kansas Entomological Society, 68, 425-436.

Dogan, Y. O., Hazir, S., Yildiz, A., Butt, T. M., \& Cakmak, I. (2017). Evaluation of entomopathogenic fungi for the control of Tetranychus urticae (Acari: Tetranychidae) and the effect of Metarhizium brunneum on the predatory mites (Acari: Phytoseiidae). Biological Control, 111, 6-12. https://doi.org/10.1016/j.biocontrol.2017.05.001

Dong, Y., Morton, J. C. Jr, Ramirez, J. L., Souza-Neto, J. A., \& Dimopoulos, G. (2012). The entomopathogenic fungus Beauveria bassiana activate toll and JAK-STAT pathway-controlled effector genes and anti-dengue activity in Aedes aegypti. Insect Biochemistry and Molecular Biology, 42, 126-132. https://doi.org/10.1016/j.ibmb.2011.11.005

Dwyer, G., Elkinton, J. S., \& Buonaccorsi, J. P. (1997). Host heterogeneity in susceptibility and disease dynamics: Tests of a mathematical model. The American Naturalist, 150, 685-707. https://doi. org/10.1086/286089

Elena, S. F. (2017). Local adaptation of plant viruses: Lessons from experimental evolution. Molecular Ecology, 26, 1711-1719.

Fenner, F., \& Fantini, B. (1999). Biological control of vertebrate pests: The history of myxomatosis, an experiment in evolution. Wallingford, UK: CABI Publishing.

Fiedler, Ż., \& Sosnowska, D. (2007). Nematophagous fungus Paecilomyces lilacinus (Thom) Samson is also a biological agent for control of greenhouse insects and mite pests. BioControl, 52, 547-558. https://doi. org/10.1007/s10526-006-9052-2

Flamini, G. (2006). Acaricides of natural origin. Part 2. Review of the literature (2002-2006). Natural Product Communications, 1, 1151-1158.

Gandon, S., \& Michalakis, Y. (2000). Evolution of parasite virulence against qualitative or quantitative host resistance. Proceedings of the Royal Society of London. Series B: Biological Sciences, 267(1447), 985-990. https://doi.org/10.1098/rspb.2000.1100

Godinho, D. P., Janssen, A., Dias, T., Cruz, C., \& Magalhães, S. (2016). Down-regulation of plant defence in a resident spider mite species 
and its effect upon con- and heterospecifics. Oecologia, 180, 161167. https://doi.org/10.1007/s00442-015-3434-z

Gotoh, T., Noda, H., Fujita, T., Iwadate, K., Higo, Y., Saito, S., \& Ohtsuka, S. (2005). Wolbachia and nuclear-nuclear interactions contribute to reproductive incompatibility in the spider mite Panonychus mori (Acari: Tetranychidae). Heredity, 94, 237-246. https://doi.org/10.1038/ sj.hdy. 6800605

Grbić, M., Van Leeuwen, T., Clark, R. M., Rombauts, S., Rouzé, P., Grbić, V., ... Van de Peer, Y. (2011). The genome of Tetranychus urticae reveals herbivorous pest adaptations. Nature, 479, 487-492. https:// doi.org/10.1038/nature10640

Greif, M. D., \& Currah, R. S. (2007). Patterns in the occurrence of saprophytic fungi carried by arthropods caught in traps baited with rotted wood and dung. Mycologia, 99, 7-19. https://doi.org/10.1080/15572 536.2007.11832595

Gurlek, S., Sevim, A., Sezgin, F. M., \& Sevim, E. (2018). Isolation and characterization of Beauveria and Metarhizium spp. from walnut fields and their pathogenicity against the codling moth, Cydia pomonella (NL.) (Lepidoptera: Tortricidae). Egyptian Journal of Biological. Pest Control, 28, 50.

Hajek, A. E., McManus, M. L., \& Delalibera, I. (2007). A review of introductions of pathogens and nematodes for classical biological control of insects and mites. Biological Control, 41, 1-13. https://doi. org/10.1016/j.biocontrol.2006.11.003

Hajek, A. E., \& St. Leger, R. J. (1994). Interactions between fungal pathogens and insect hosts. Annual Review of Entomology, 39, 293-322. https://doi.org/10.1146/annurev.en.39.010194.001453

Hawley, D. M., \& Altizer, S. M. (2011). Disease ecology meets ecological immunology: Understanding the links between organismal immunity and infection dynamics in natural populations. Functional Ecology, 25, 48-60. https://doi.org/10.1111/j.1365-2435.2010.01753.x

Inglis, G. D., Goettel, M. S., Butt, T. M., \& Strasser, H. (2001). Use of hyphomycetous fungi for managing insect pests. In T. M. Butt, C. Jackson, \& N. Magan (Eds.), Fungi as biocontrol agents: Progress problems and potential (pp. 23-69). Wallingford, UK: CABI Publishing.

Irigaray, F., Marco-Mancebon, V., \& Perez-Moreno, I. (2003). The entomopathogenic fungus Beauveria bassiana and its compatibility with triflumuron: Effects on the two-spotted spider mite Tetranychus urticae. Biological Control, 26, 168-173. https://doi.org/10.1016/ S1049-9644(02)00123-8

Klingen, I., \& Westrum, K. (2007). The effect of pesticides used in strawberries on the phytophagous mite Tetranychus urticae (Acari: Tetranychidae) and its fungal natural enemy Neozygites floridana (Zygomycetes: Entomophthorales). Biological Control, 43, 222-230. https://doi.org/10.1016/j.biocontrol.2007.07.013

Lacey, L. A., Frutos, R., Kaya, H. K., \& Vail, P. (2001). Insect pathogens as biological control agents: Do they have a future? Biological Control, 21, 230-248. https://doi.org/10.1006/bcon.2001.0938

Li, T., Chen, X.-L., \& Hong, X.-Y. (2009). Population genetic structure of Tetranychus urticae and its sibling species Tetranychus cinnabaribus (Acari: Tetranychidae) in China as inferred from microsatellite data. Annals of the Entomological Society of America, 102, 674-683.

Li, Y. Y., Floate, K. D., Fields, P. G., \& Pang, B. P. (2014). Review of treatment methods to remove Wolbachia bacteria from arthropods. Symbiosis, 62, 1-15. https://doi.org/10.1007/s13199-014-0267-1

Maniania, N. K., Bugeme, D. M., Wekesa, V. W., Delalibera, I., \& Knapp, M. (2008). Role of entomopathogenic fungi in the control of Tetranychus evansi and Tetranychus urticae (Acari: Tetranychidae), pests of horticultural crops. Experimental and Applied Acarology, 46, 259-274. https ://doi.org/10.1007/s10493-008-9180-8

Meyling, N. V., \& Eilenberg, J. (2007). Ecology of the entomopathogenic fungi Beauveria bassiana and Metarhizium anisopliae in temperate agroecosystems: Potential for conservation biological control. Biological Control, 43, 145-155. https://doi.org/10.1016/j.bioco ntrol.2007.07.007
Migeon, A., \& Dorkeld, F. (2006-2017). Spider Mites Web: A comprehensive database for the Tetranychidae. Retrieved from http://www. montpellier.inra.fr/CBGP/spmweb/

Migeon, A., Ferragut, F., Escudero-Colomar, L. A., Fiaboe, K., Knapp, M., de Moraes, G. J., ... Navajas, M. (2009). Modelling the potential distribution of the invasive tomato red spider mite, Tetranychus evansi (Acari: Tetranychidae). Experimental and Applied Acarology, 48, 199212. https://doi.org/10.1007/s10493-008-9229-8

Miller, M. R., White, A., \& Boots, M. (2006). The evolution of parasites in response to tolerance in their hosts: The good, the bad, and apparent commensalism. Evolution, 60, 945-956. https://doi. org/10.1111/j.0014-3820.2006.tb01173.x

Milner, R. (1982). On the occurrence of pea aphids, Acyrthosiphon pisum, resistant to isolates of the fungal pathogen Erynia neoaphidis. Entomologia Experimentalis Et Applicata, 32, 23-27. https://doi. org/10.1111/j.1570-7458.1982.tb03176.x

Milner, R. (1985). Distribution in time and space of resistance to the pathogenic fungus Erynia neoaphidis in the pea aphid Acyrthosiphon pisum. Entomologia Experimentalis Et Applicata, 37, 235-240. https:// doi.org/10.1111/j.1570-7458.1985.tb03480.x

Moscardi, F. (1999). Assessment of the application of baculoviruses for control of Lepidoptera. Annual Review of Entomology, 44, 257-289. https://doi.org/10.1146/annurev.ento.44.1.257

Opit, G. P., Chen, Y., Williams, K. A., Nechols, J. R., \& Margolies, D. C. (2005). Plant age, fertilization, and biological control affect damage caused by twospotted spider mites on ivy geranium: Development of an action threshold. Journal of the American Society for Horticultural Science, 130, 159-166. https://doi.org/10.21273/ JASHS.130.2.159

Ormond, E. L., Thomas, A. P. M., Pugh, P. J. A., Pell, J. K., \& Roy, H. E. (2010). A fungal pathogen in time and space: The population dynamics of Beauveria bassiana in a conifer forest. FEMS Microbiology Ecology, 74, 146-154. https://doi.org/10.1111/j.1574-6941.2010.00939.x

Park, Y. L., \& Lee, J. H. (2002). Leaf cell and tissue damage of cucumber caused by twospotted spider mite (Acari: Tetranychidae). Journal of Economic Entomology, 95, 952-957. https://doi.org/10.1093/jee/95.5.952

Park, Y. L., \& Lee, J. H. (2005). Impact of two-spotted spider mite (Acari: Tetranychidae) on growth and productivity of glasshouse cucumbers. Journal of Economic Entomology, 98, 457-463. https://doi. org/10.1093/jee/98.2.457

Park, Y. L., \& Lee, J. H. (2007). Seasonal dynamics of economic injury levels for Tetranychus urticae Koch (Acari, Tetranychidae) on Cucumis sativus L. Journal of Applied Entomology, 131, 588-592. https://doi. org/10.1111/j.1439-0418.2007.01217.x

Parker, B. J., Barribeau, S. M., Laughton, A. M., de Roode, J. C., \& Gerardo, N. M. (2011). Non-immunological defense in an evolutionary framework. Trends in Ecology \& Evolution, 26, 242-248. https:// doi.org/10.1016/j.tree.2011.02.005

Parolin, P., Bresch, C., Desneux, N., Brun, R., Bout, A., Boll, R., \& Poncet, C. (2012). Secondary plants used in biological control: A review. International Journal of Pest Management, 58, 91-100. https://doi. org/10.1080/09670874.2012.659229

Perinotto, W., Angelo, I., Golo, P., Quinelato, S., Camargo, M., Sá, F., \& Bittencourt, V. (2012). Susceptibility of different populations of ticks to entomopathogenic fungi. Experimental Parasitology, 130, 257-260. https://doi.org/10.1016/j.exppara.2011.12.003

Raberg, L., Sim, D., \& Read, A. F. (2007). Disentangling genetic variation for resistance and tolerance to infectious diseases in animals. Science, 318, 812-814. https://doi.org/10.1126/science.1148526

Rausher, M. D. (2001). Co-evolution and plant resistance to natural enemies. Nature, 411, 857-864. https://doi.org/10.1038/35081193

Read, A. P. (1995). Genetics and evolution of infectious diseases in natural populations: Group report. In B. T. Grenfell, \& A. P. Dobson (Eds.), Ecology of infectious diseases in natural populations (pp. 450-477). Cambridge, UK: Cambridge University Press. 
Read, A. F., Graham, A. L., \& Raberg, L. (2008). Animal defenses against infectious agents: Is damage control more important than pathogen control? PLoS Biology, 6, 2638-2641. https://doi.org/10.1371/journ al.pbio. 1000004

Rehner, S. A. (2005). Phylogenetics of the insect pathogenic genus Beauveria. In F. E. Vega, \& M. Blackwell (Eds.), Insect-fungal associations: Ecology and evolution (pp. 3-27). New York, NY: Oxford University Press.

Ribeiro, A. E. L., Gondim, M. G. C. Jr, Calderan, E., \& Delalibera, I. Jr (2009). Host range of Neozygites floridana isolates (Zygomycetes: Entomophthorales) to spider mites. Journal of Invertebrate Pathology, 102, 196-202. https://doi.org/10.1016/j.jip.2009.08.012

Roberts, D. W., \& Leger, R. J. S. (2004). Metarhizium spp., cosmopolitan insect-pathogenic fungi: Mycological aspects. In A. I. Laskin, J. W. Bennet, \& G. M. Gadd (Eds.), Advances in applied microbiology (pp. 1-70). San Diego, CA: Academic Press.

Santos-Matos, G., Wybouw, N., Martins, N. E., Zélé, F., Riga, M., Leitao, A. B., ... Sucena, E. (2017). Tetranychus urticae mites do not mount an induced immune response against bacteria. Proceedings of the Royal Society B-Biological Sciences, 284, 20170401.

Sarmento, R. A., Lemos, F., Bleeker, P. M., Schuurink, R. C., Pallini, A., Oliveira, M. G. A., ... Janssen, A. (2011). A herbivore that manipulates plant defence. Ecology Letters, 14, 229-236. https://doi. org/10.1111/j.1461-0248.2010.01575.x

Seiedy, M. (2014). Feeding preference of Phytoseiulus persimilis AthiasHenriot (Acari: Phytosei-idae) towards untreated and Beauveria bassiana-treated Tetranychus urticae (Acari: Tetranychidae) on cucumber leaves. Persian Journal of Acarology, 3, 91-97.

Seiedy, M., Saboori, A., \& Allahyari, H. (2012). Interactions of two natural enemies of Tetranychus urticae, the fungal entomopathogen Beauveria bassiana and the predatory mite, Phytoseiulus persimilis. Biocontrol Science and Technology, 22, 873-882.

Seiedy, M., Saboori, A., \& Zahedi-Golpayegani, A. (2013). Olfactory response of Phytoseiulus persimilis (Acari: Phytoseiidae) to untreated and Beauveria bassiana-treated Tetranychus urticae (Acari: Tetranychidae). Experimental and Applied Acarology, 60, 219-227. https://doi.org/10.1007/s10493-012-9652-8

Shi, W. B., \& Feng, M. G. (2004). Lethal effect of Beauveria bassiana, Metarhizium anisopliae, and Paecilomyces fumosoroseus on the eggs of Tetranychus cinnabarinus (Acari: Tetranychidae) with a description of a mite egg bioassay system. Biological Control, 30, 165-173. https:// doi.org/10.1016/j.biocontrol.2004.01.017

Shi, W.-B., Jiang, Y., \& Feng, M.-G. (2005). Compatibility of ten acaricides with Beauveria bassiana and enhancement of fungal infection to Tetranychus cinnabarinus (Acari: Tetranychidae) eggs by sublethal application rates of pyridaben. Applied Entomology and Zoology, 40, 659-666. https://doi.org/10.1303/aez.2005.659

Shi, W.-B., Zhang, L., \& Feng, M.-G. (2008). Time-concentration-mortality responses of carmine spider mite (Acari: Tetranychidae) females to three hypocrealean fungi as biocontrol agents. Biological Control, 46, 495-501. https://doi.org/10.1016/j.biocontrol.2008.04.006

Shin, T. Y., Bae, S. M., Kim, D. J., Yun, H. G., \& Woo, S. D. (2017). Evaluation of virulence, tolerance to environmental factors and antimicrobial activities of entomopathogenic fungi against two-spotted spider mite, Tetranychus urticae. Mycoscience, 58, 204-212. https:// doi.org/10.1016/j.myc.2017.02.002

Sorci, G., Moller, A. P., \& Boulinier, T. (1997). Genetics of host-parasite interactions. Trends in Ecology \& Evolution, 12, 196-200. https://doi. org/10.1016/S0169-5347(97)01056-2

Stevens, L., \& Rizzo, D. M. (2008). Local adaptation to biocontrol agents: A multi-objective data-driven optimization model for the evolution of resistance. Ecological Complexity, 5, 252-259. https://doi. org/10.1016/j.ecocom.2008.04.002

Tabashnik, B. E. (1994). Evolution of resistance to Bacillus thuringiensis. Annual Review of Entomology, 39, 47-79. https://doi.org/10.1146/ annurev.en.39.010194.000403
Ullah, M. S., \& Lim, U. T. (2017). Synergism of Beauveria bassiana and Phytoseiulus persimilis in control of Tetranychus urticae on bean plants. Systematic and Applied Acarology, 22, 1924-1935. https://doi. org/10.11158/saa.22.11.11

Uma Devi, K., Padmavathi, J., Uma Maheswara Rao, C., Khan, A. A. P., \& Mohan, M. C. (2008). A study of host specificity in the entomopathogenic fungus Beauveria bassiana (Hypocreales, Clavicipitaceae). Biocontrol Science and Technology, 18, 975-989.

Van Der Geest, L. P., Moraes, G. J., Navia, D., \& Tanzini, M. R. (2002). New records of pathogenic fungi in mites (Arachnida: Acari) from Brazil. Neotropical Entomology, 31, 493-495. https://doi.org/10.1590/ S1519-566X2002000300025

Van Leeuwen, T., Vontas, J., Tsagkarakou, A., Dermauw, W., \& Tirry, L. (2010). Acaricide resistance mechanisms in the two-spotted spider mite Tetranychus urticae and other important Acari: A review. Insect Biochemistry and Molecular Biology, 40, 563-572. https://doi. org/10.1016/j.ibmb.2010.05.008

Vega, F. E., Goettel, M. S., Blackwell, M., Chandler, D., Jackson, M. A., Keller, S., ... Roy, H. E. (2009). Fungal entomopathogens: New insights on their ecology. Fungal Ecology, 2, 149-159. https://doi. org/10.1016/j.funeco.2009.05.001

Vergel, S. J. N., Bustos, R. A., Rodriguez, C. D., \& Cantor, R. F. (2011). Laboratory and greenhouse evaluation of the entomopathogenic fungi and garlic-pepper extract on the predatory mites, Phytoseiulus persimilis and Neoseiulus californicus and their effect on the spider mite Tetranychus urticae. Biological Control, 57, 143-149. https://doi. org/10.1016/j.biocontrol.2011.02.007

Vezilier, J., Nicot, A., Gandon, S., \& Rivero, A. (2015). Plasmodium infection brings forward mosquito oviposition. Biology Letters, 11, 20140840.

Wang, C. S., Shah, F. A., Patel, N., Li, Z. Z., \& Butt, T. M. (2003). Molecular investigation on strain genetic relatedness and population structure of Beauveria bassiana. Environmental Microbiology, 5, 908-915. https ://doi.org/10.1046/j.1462-2920.2003.00485.x

Weihrauch, F. (2005). Evaluation of a damage threshold for two-spotted spider mites, Tetranychus urticae Koch (Acari: Tetranychidae), in hop culture. Annals of Applied Biology, 146, 501-509. https://doi. org/10.1111/j.1744-7348.2005.040163.x

Wu, S., Xie, H., Li, M., Xu, X., \& Lei, Z. (2016). Highly virulent Beauveria bassiana strains against the two-spotted spider mite, Tetranychus urticae, show no pathogenicity against five phytoseiid mite species. Experimental and Applied Acarology, 70, 421-435. https://doi. org/10.1007/s10493-016-0090-x

Zélé, F., Santos, I., Olivieri, I., Weill, M., Duron, O., \& Magalhães, S. (2018a). Endosymbiont diversity and prevalence in herbivorous spider mite populations in South-Western Europe. FEMS Microbiology Ecology, 94, fiy015. https://doi.org/10.1093/femsec/fiy015

Zélé, F., Santos, J. L., Godinho, D. P., \& Magalhães, S. (2018b). Wolbachia both aids and hampers the performance of spider mites on different host plants. FEMS Microbiology Ecology, 94, fiy187. https://doi. org/10.1093/femsec/fiy187

Zindel, R., Gottlieb, Y., \& Aebi, A. (2011). Arthropod symbioses: A neglected parameter in pest- and disease-control programmes. Journal of Applied Ecology, 48, 864-872. https://doi. org/10.1111/j.1365-2664.2011.01984.x

How to cite this article: Zélé F, Altıntaş M, Santos I, Cakmak I, Magalhães S. Inter- and intraspecific variation of spider mite susceptibility to fungal infections: Implications for the long-term success of biological control. Ecol Evol. 2020;10:3209-3221. https://doi.org/10.1002/ece3.5958 